\title{
Enhancing Literacy with Student Models
}

\author{
Christopher Horger
}

American University of Sharjah

\begin{abstract}
North American writing programs in universities outside of North America face a number of pedagogical obstacles in the effective teaching of rhetoric, not the least of which are textbooks imported from the United States. These textbooks are written primarily by Americans, for Americans, about all things American, but they completely miss the target audience of students outside of that social and cultural context. Any teacher who has ever used a text with model essays designed for students within the US, knows that outside of that context problems abound. Everything from subtle cultural allusions, or even more direct references to sport terms or celebrity names, to choices of argumentative political or social topics, one virtually needs to have grown up in that culture to make sense of the texts.

Here in the writing program at the American University of Sharjah, where English is the second language to the predominantly native Arabic-speaking students, many have found that an effective way to teach writing is by using student models. This paper will discuss the many advantages of using student models, from more accessible language to which students can readily connect, and having topics of a more regional interest, to having a more transparent glimpse into the writing process, as well as enabling students to see their peers' writing discussed seriously in the classroom.
\end{abstract}

Keywords: English for Academic Purposes; Higher Education; literacy 